\title{
Biological community structure on patch reefs in Biscayne National Park, FL, USA
}

\author{
Ilsa B. Kuffner • Rikki Grober-Dunsmore • \\ John C. Brock • T. Don Hickey
}

Received: 6 August 2008 / Accepted: 6 April 2009 / Published online: 28 April 2009

(C) The Author(s) 2009. This article is published with open access at Springerlink.com

\begin{abstract}
Coral reef ecosystem management benefits from continual quantitative assessment of the resources being managed, plus assessment of factors that affect distribution patterns of organisms in the ecosystem. In this study, we investigate the relationships among physical, benthic, and fish variables in an effort to help explain the distribution patterns of organisms on patch reefs within Biscayne National Park, FL, USA. We visited a total of 196 randomly selected sampling stations on 12 shallow $(<10 \mathrm{~m})$ patch reefs and measured physical variables (e.g., substratum rugosity, substratum type) and benthic and fish community variables. We also incorporated data on substratum rugosity collected remotely via airborne laser surveying (Experimental Advanced Airborne Research Lidar-EAARL). Across all stations, only weak relationships were found between physical, benthic cover, and fish assemblage variables.
\end{abstract}

I. B. Kuffner $(\varangle)$ · T. D. Hickey

US Geological Survey, 600 4th St. South,

St. Petersburg, FL 33701, USA

e-mail: ikuffner@usgs.gov

R. Grober-Dunsmore

Institute of Applied Sciences, University of the South

Pacific, Suva, Fiji

J. C. Brock

US Geological Survey National Center, 12201 Sunrise

Valley Dr., Reston, VA 20192, USA
Much of the variance was attributable to a "reef effect," meaning that community structure and organism abundances were more variable at stations among reefs than within reefs. However, when the reef effect was accounted for and removed statistically, patterns were detected. Within reefs, juvenile scarids were most abundant at stations with high coverage of the fleshy macroalgae Dictyota spp., and the calcified alga Halimeda tuna was most abundant at stations with low EAARL rugosity. Explanations for the overwhelming importance of "reef" in explaining variance in our dataset could include the stochastic arrangement of organisms on patch reefs related to variable larval recruitment in space and time and/or strong historical effects due to patchy disturbances (e.g., hurricanes, fishing), as well as legacy effects of prior residents ("priority" effects).

Keywords Benthic community structure • Marine protected areas $\cdot$ Overfishing $\cdot$ Rugosity

\section{Introduction}

Coral reef ecosystems around the world are degrading due to a multitude of stressors (Wilkinson 1999; Hoegh-Guldberg 1999; Pandolfi et al. 2003), and coral reefs in the Caribbean basin are particularly in peril (Hughes 1994; Porter et al. 2002; Gardner et al. 2003; Pandolfi et al. 2005). Degra- 
dation has continued despite concerted efforts at resource management (Keller and Causey 2005). Understanding how and why species are distributed across the seascape is critical to managing coral reef ecosystems.

Controversy exists over what variables influence community structure on reefs and the amount of time these communities spend at equilibrium (Connell 1978). Study results are often dependent upon scale and/or the range of habitats being considered (Syms 1995; Eagle et al. 2001; Chittaro 2004). Generally, one body of literature supports niche diversification and predicts highly ordered communities (e.g., Connolly et al. 2005), while another supports a more stochastic view, highlighting the importance of spatially and temporally variable recruitment of larvae (e.g., Sale and Douglas 1984; Doherty and Fowler 1994). However, with backgrounds of considerable temporal and spatial variability in fish and benthic community structure, many studies support human extraction and alteration of habitat and water quality as determinants of coral reef status (McClanahan 1994; Chapman and Kramer 2001; Halpern and Warner 2002; Graham et al. 2006; Pandolfi and Jackson 2006; Maliao et al. 2008). Human disturbance could, in effect, mask any natural relationships between species and their habitat by altering the limiting factors that control populations.

There are over 4,000 patch reefs in the northern Florida Keys (Marszalek et al. 1977), highlighting this ecotype as one of importance to the Florida reef tract (Jones 1977). Other researchers have documented these patch reefs as being biologically diverse with substantial live coral compared to outer-tract reefs (Miller et al. 2000a). Fisheries and fish habitat (Ault et al. 2001) and benthic community structure (Chiappone and Sullivan 1997; Miller et al. 2000b) assessment efforts conducted over the last few decades have underrepresented the patch reef habitat; thus, we decided on this habitat as the focus of our study. Though there are a fair number of reports including data on coral populations in Biscayne National Park (BNP; Burns 1985; Porter and Meier 1992; Greenstein and Pandolfi 1997; Ginsburg et al. 2001; Lirman and Fong 2007), studies on invertebrate and macroalgal communities are few.
The purpose of this study was, first, to provide a detailed description of patch reef community structure in BNP and, second, to examine the relationships among physical, benthic community, and fish assemblage variables. Using in situ diver surveys, we measured fish abundance at the species level, percent benthic cover by coral, algae, and encrusting invertebrates, coral recruit density, and other variables at 12 patch reefs within BNP. Data were compiled for 196 stations where physical and benthic variables were measured, including a subset of 119 stations where fish were also surveyed. We hypothesized that the difference in variables between reefs would be insignificant since we expected the patch reefs to represent a homogeneous habitat. We anticipated that specific relationships between fish and benthic variables would be evident, predicting low fleshy algal abundance at stations where herbivorous fish were abundant (and conversely more suitable settlement substratum for coral larvae) and high fish abundance at stations where gorgonians were dense. We also expected to see significant correlations between benthic variables and the physical habitat, predicting that macroalgae would be more abundant on topographically flatter parts of the reef. The relationships between physical (e.g., rugosity) and fish variables are the subject of a previous paper (Kuffner et al. 2007) and are not discussed here.

Our results were different than expected, showing more variance between rather than within reefs and revealing no strong relationships between physical, benthic, and fish variables. We discuss possible mechanisms that could help explain the patterns in community structure and the lack of correlations between variables that we observed on these patch reefs and suggest possible mechanisms influencing patch reef community structure in BNP.

\section{Materials and methods}

Field assessment of physical, benthic, and fish variables

Underwater surveys were conducted via scuba diving on 12 small $(\approx 1$ ha) patch reefs in Biscayne 
Table 1 GPS locations and descriptive data for patch reefs surveyed September 9 to 16,2003

See Kuffner et al. (2007) or http://pubs.usgs.gov/of/ 2008/1330/ (Kuffner et al. 2008) for a map of the study area

\begin{tabular}{lccccc}
\hline Reef & Northings & Eastings & $\begin{array}{l}\text { Distance to } \\
\text { next reef }(\mathrm{m})\end{array}$ & $\begin{array}{l}\text { Depth } \\
(\mathrm{m}(\mathrm{SE}))\end{array}$ & $\begin{array}{l}\text { Area } \\
\left(\mathrm{m}^{2}\right)\end{array}$ \\
\hline Bravo & 2809202.30 & 584641.20 & 83.56 & $3.69(0.11)$ & $4,748.6$ \\
Delta & 2808991.35 & 584388.60 & 109.56 & $4.13(0.17)$ & $2,814.0$ \\
Echo & 2808892.40 & 584368.30 & 109.56 & $4.48(0.15)$ & $2,590.3$ \\
Golf & 2807699.95 & 584340.15 & 130.99 & $4.71(0.30)$ & $3,633.6$ \\
Hotel & 2807651.60 & 583061.90 & 88.41 & $4.37(0.13)$ & $1,905.5$ \\
India & 2807639.50 & 583703.30 & 86.84 & $3.86(0.18)$ & $2,499.0$ \\
Juliet & 2807629.65 & 584101.45 & 72.14 & $4.59(0.22)$ & $1,691.5$ \\
Kilo & 2807372.00 & 584094.60 & 144.16 & $4.07(0.16)$ & $3,406.0$ \\
Lima & 2807292.15 & 584239.60 & 163.13 & $5.33(0.33)$ & $3,609.3$ \\
November & 2805548.00 & 583056.85 & 148.97 & $3.71(0.17)$ & $3,484.4$ \\
Oscar & 2805533.50 & 582856.80 & 159.33 & $4.28(0.25)$ & $3,379.8$ \\
Papa & 2804483.40 & 583245.85 & 76.47 & $5.46(0.24)$ & $2,350.3$ \\
\hline
\end{tabular}

National Park, FL, USA, from September 9 to 16, 2003 (see http://pubs.usgs.gov/of/2008/1330/ for a map of the study area). Patch reefs in the northern Florida reef tract are generally dome-shaped and surrounded by dense sea grass beds (Jaap 1984). Reefs were selected based upon similarities in average depth (3-6 m), area, positioning across the reef shelf, reef shape, and other potentially confounding variables (Table 1). A four-person research team visited each reef once to measure physical and biological community variables using accepted survey methods (Table 2).

Variables were measured at $n=16$ randomly chosen global positioning system (GPS) coordinates (stations) per reef, as described by Kuffner et al. (2007). Randomized sampling is critical to survey design in order to avoid the problems associated with fixed-interval and haphazard sampling often employed in these types of studies (Lewis 2004). The GPS coordinates for the stations were

Table 2 Field survey methods employed to measure community attributes in Biscayne National Park, FL, USA

\begin{tabular}{|c|c|}
\hline Variable & Survey method \\
\hline Chain rugosity & $\begin{array}{l}\text { After Risk (1972), rugosity was estimated by laying a 10-m transect tape across } \\
\text { reef in east-west direction with the 5-m mark over the station marker; using a } \\
\text { 1-m chain with } 1-\mathrm{cm} \text { links, we estimated contoured distance by serially } \\
\text { deploying the chain across the substratum; rugosity was calculated as the ratio } \\
\text { between contoured and linear distance }\end{array}$ \\
\hline Substratum type & $\begin{array}{l}\text { Percent makeup of the substratum was estimated using } 1-\mathrm{m}^{2} \text { quadrat; categories } \\
\text { included cemented reef, coral rubble (three size classes), pavement, and sand }\end{array}$ \\
\hline Algae, benthic invertebrates, and coral & $\begin{array}{l}\text { Species-level percent cover of algae, benthic invertebrates, and live coral } \\
\text { estimated in } 0.25 \times 0.25 \text {-m quadrats; number of coral recruits } \\
\text { (defined as }<1 \text {-cm diameter) was counted within the same quadrats; coral } \\
\text { species richness was estimated by thoroughly searching over the whole patch } \\
\text { reef while transiting between stations during each } 2.5 \text {-h dive }\end{array}$ \\
\hline Urchins and gorgonians & $\begin{array}{l}\text { Number of urchins by species was counted within } 0.5 \times 0.5 \text {-m quadrats; } \\
\text { gorgonian abundance and volume were estimated within the same quadrats, } \\
\text { identified to lowest taxonomic level possible in the field (at least genus); } \\
\text { gorgonian volume was estimated by measuring maximum dimensions } \\
\text { (length } \times \text { width } \times \text { height) with a 3-m tailors' tape measure }\end{array}$ \\
\hline Fish & $\begin{array}{l}\text { Bohnsack and Bannerot (1986) point count method was used to estimate } \\
\text { abundance and size of fish for each species observed within an imaginary } \\
\text { 7.5-m-radius cylinder from the benthos to the water-column surface }\end{array}$ \\
\hline
\end{tabular}

One sample for each variable (i.e., rugosity transect, fish count, quadrat) was performed per station 
uploaded to a handheld Garmin Map 76 GPS unit equipped with the Wide Area Augmentation System and used to navigate a small vessel to deliver marker buoys to each station. Maps were prepared for each reef so that field personnel could use them to place marker buoys and navigate underwater from station to station. Four scuba divers with expert capabilities in the identification of coral, algae, reef fish, gorgonians, and geologic structure worked simultaneously, rotating from station to station. All surveys were conducted between 0900 and 1800 EST. Physical, benthic, and fish data are available as geographic information system layers online in a noninterpretive product: http://pubs.usgs.gov/of/2008/1330/ (Kuffner et al. 2008).

Fish surveys were conducted using the Bohnsack and Bannerot (1986) point count method, wherein a diver sits stationary in the middle of a 7.5-m-radius imaginary cylinder, recording fish species observed in a 5-min period, and then estimates length and abundance for each recorded species for the following $10 \mathrm{~min}$. Occasionally, a point count cylinder included more than one station due to the random assignment of stations within reefs. When a cylinder contained more than one station, the fish data were randomly assigned to one of the stations, and the other station was left with missing values for fish variables. Thus, the number of stations with fish data varied from ten to 13 per reef.

\section{EAARL measurement of substratum rugosity}

The Experimental Advanced Airborne Research Lidar (EAARL) data were collected in August 2002, and details of the data acquisition and processing are described elsewhere (Brock et al. 2006a; Kuffner et al. 2007) as well as the data themselves (Brock et al. 2006b). Briefly, the National Aeronautics and Space Administration EAARL equipment was flown aboard an airplane at 300-m altitude, collecting 10-cm-diameter laserspot elevation soundings at a spatial density of approximately one sounding per square meter. Using an approach based upon Dahl's surface index, defined as the ratio of the actual surface area to that of a flat horizontal two-dimensional plane with similar boundaries (Dahl 1973), rugosity was estimated from lidar-derived digital elevation models at $1-\mathrm{m}$ cell resolution.

Statistical analyses

Simple linear regression was used to test specific $a$ priori hypotheses regarding relationships between individual physical, benthic, and fish variables. When the assumptions of linear regression were violated (e.g., residuals not normally distributed), the data were transformed as necessary. Oneway analysis of variance (ANOVA) was used to assess differences in individual variables between reefs, followed by Tukey's honestly significant difference (HSD) test to find the differences using a family alpha $=0.05$. When the data failed to meet the assumptions of the parametric tests despite transformations, nonparametric KruskalWallis ANOVA was used instead, followed by Kruskal-Wallis all-pairwise comparisons (alpha = $0.05)$. When there was a pronounced pattern in the plot of regression residuals against "reef," two-way ANOVA was utilized to explore the data further: the explanatory variables were categorized by dividing the ordered data into thirds (e.g., low, medium, and high Dictyota spp. cover), with the two-way models including the fixed factors (e.g., "reef," "Dictyota category") and the interaction term.

To assess overall patterns in physical variables and biological community structure and their relation to each other, multivariate methods available in PRIMER v.6 software (Clarke and Warwick 2001) were employed. Physical variables in this analysis included all categories of substratum composition (Table 2), rugosity measured with the chain-transect method, rugosity measured with EAARL at the 2- and 10-m scale (Kuffner et al. 2007), and the reef attributes of reef area, lidar-determined depth, and distance to nearest reef. Benthic variables included are presented in Table 3. For fish variables, data were aggregated at the family level, separating juveniles and adults for families Acanthuridae, Serranidae, Haemulidae, Scaridae, and Lutjanidae, and not differentiating life stage for families Pomacanthidae, Chaetodontidae, Pomacentridae, Mullidae, and Labridae. With PRIMER, we calculated 


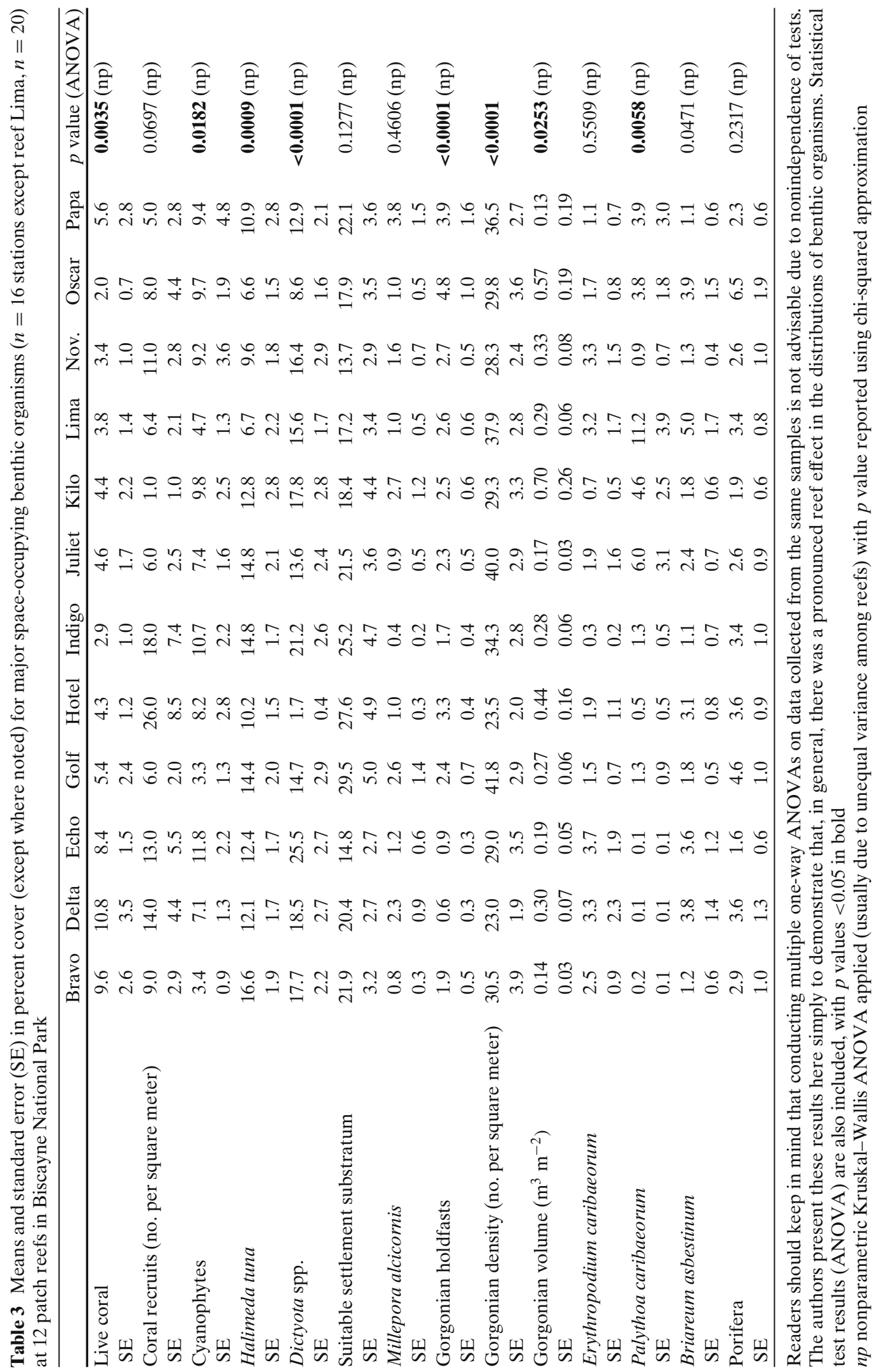


Euclidean distances for physical variables that had been $\log (x+1)$-transformed (except for the distance to nearest reef) and normalized, BrayCurtis similarity on square-root-transformed data for benthic community variables, and Bray-Curtis similarity on $\log (x+1)$-transformed fish abundance data to create triangular resemblance matrices. To test for significance of the "reef" factor, we used PRIMER's ANOSIM procedure, which calculates a global $R$ statistic that reflects the differences in variability between groups, compared to within groups (so $R$ values are proportional to differences between the groups), and checks for significance of $R$ using permutation tests (Clarke and Warwick 2001). Nonmetric multidimensional scaling (MDS) was used on matrices derived from averaging reefs to visualize the similarities among reefs. To test for significant relationships between the resemblance matrices for physical, benthic, and fish variables averaged for each reef, we used PRIMER's RELATE procedure which also calculates a global $R$ statistic and checks for significance of $R$ using permutation tests.

\section{Results}

Physical variables

Substratum surveys revealed that the patch reefs were generally dominated by cemented reef (grand mean $47.3 \pm 2.2 \%$ cover) and pavement $(20.1 \pm 2.1 \%)$, with varying amounts of rubble, boulders, and sand (Fig. 1). Reefs differed significantly in the amount of cemented reef (one-way ANOVA $F=5.57, p<0.0001$ ) and pavement (nonparametric one-way ANOVA Kruskal-Wallis statistic $=43.6, p<0.0001)$. Allpairwise comparisons (Tukey's HSD groupings) revealed that reef Lima had significantly less cemented reef than all reefs except November, Oscar, Bravo, and Echo. Lima also had significantly more pavement (Kruskal-Wallis allpairwise groupings) than India, Hotel, Juliet, Oscar, Delta, and November. Both chaintransect rugosity and EAARL rugosity were significantly different among reefs (KruskalWallis statistic $=43.6$ and 41.3, respectively, both
Fig. 1 Mean percent cover of substratum types on 12 patch reefs in Biscayne National Park. Percent cover within 1-m² quadrats estimated at randomly chosen stations ( $n=16$ per reef except reef $\mathrm{L}, n=20$ )

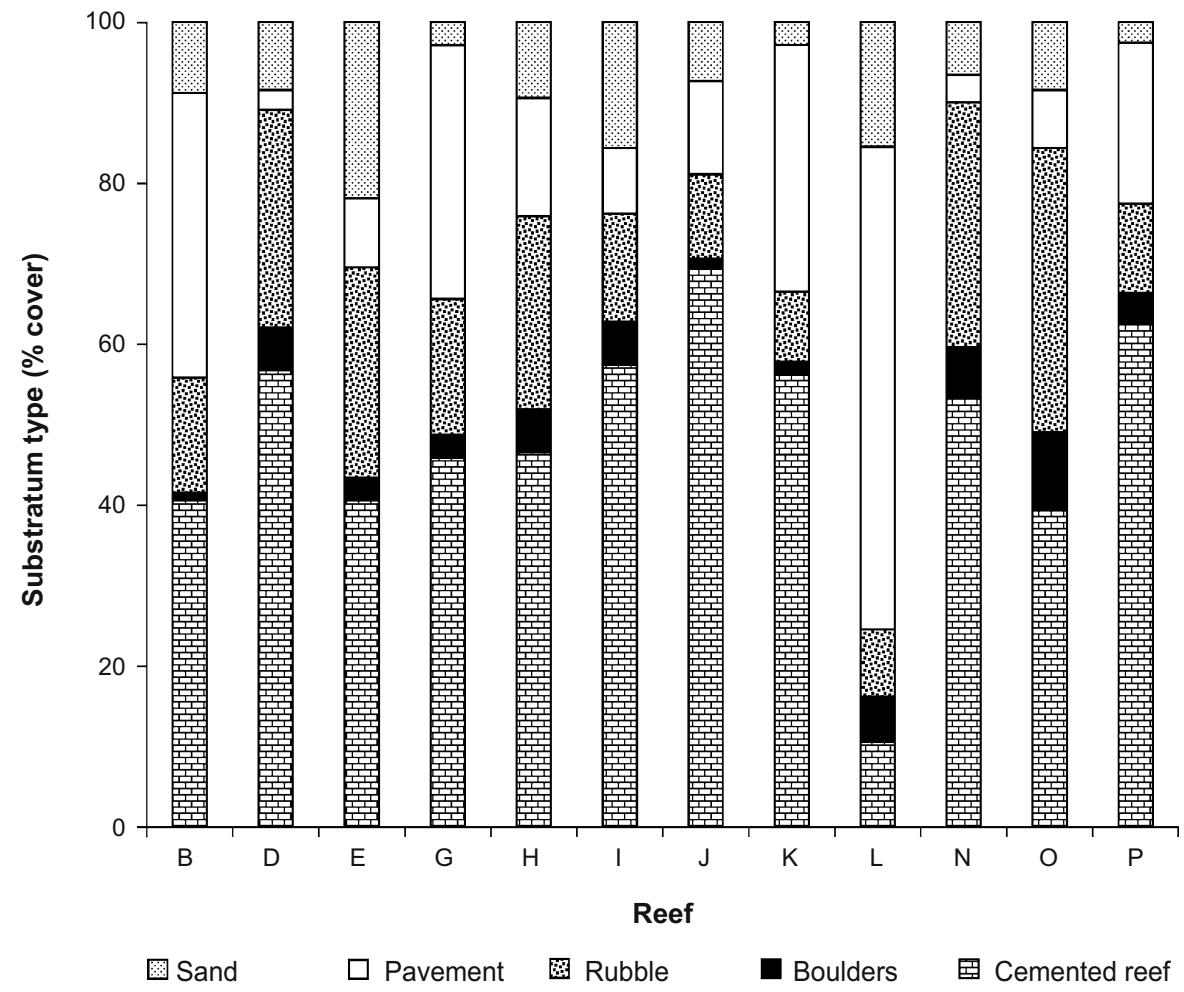


$p<0.0001$ ), but the all-pairwise comparison tests did not give the same groupings. Chaintransect rugosity results indicated that reefs Oscar, Juliet, Papa, Golf, and Kilo were all more rugose than Hotel, whereas EAARL rugosity results characterized reef Juliet as more rugose than Delta, November, Oscar, and Bravo (the discrepancy between the chain and EAARL rugosity measurements is discussed in Kuffner et al. (2007)). We found significant effects of "reef" in explaining differences among stations when all of the physical variables were combined (ANOSIM Global $R=0.415, p=0.001$ ), and the similarities among reefs with regards to physical variables can be visualized in the MDS plot (Fig. 2).

\section{Benthic variables}

The benthic community observed on the patch reefs was largely dominated by macrophytes, encrusting invertebrates, and "suitable settlement substratum" (SSS) found beneath a substantial canopy of gorgonians (Table 3). A mean of $20.8 \pm$ $1.1 \%$ of the bottom was assigned to the category SSS, defined as hard substratum covered mostly in crustose coralline algae (CCA) and lacking sediments $>1 \mathrm{~mm}$ deep, macroalgae, or thick turf algae as previously described in Kuffner et al. (2006). This category was considered to be an index of suitable settlement substratum for coral larvae and is analogous to the "cropped substratum" category of Williams and Polunin (2001).

Macroalgae occupied a large portion of space on the reefs we surveyed, especially Dictyota spp. (grand mean $=15.4 \pm 0.8 \%$ cover) and Halimeda tuna (grand mean $=11.7 \pm 0.6 \%$ cover). Reefs significantly differed in the extent of Dictyota spp. coverage (Kruskal-Wallis, $p<$ 0.0001). Cyanophytes were also fairly abundant (grand mean $=7.8 \pm 0.7 \%$ cover). Live scleractinian corals only accounted for $5.8 \pm 0.6 \%$ of the benthos. Encrusting invertebrates (Porifera, Briareum asbestinum, Palythoa caribaeorum, Erythropodium caribaeorum, gorgonian hold-
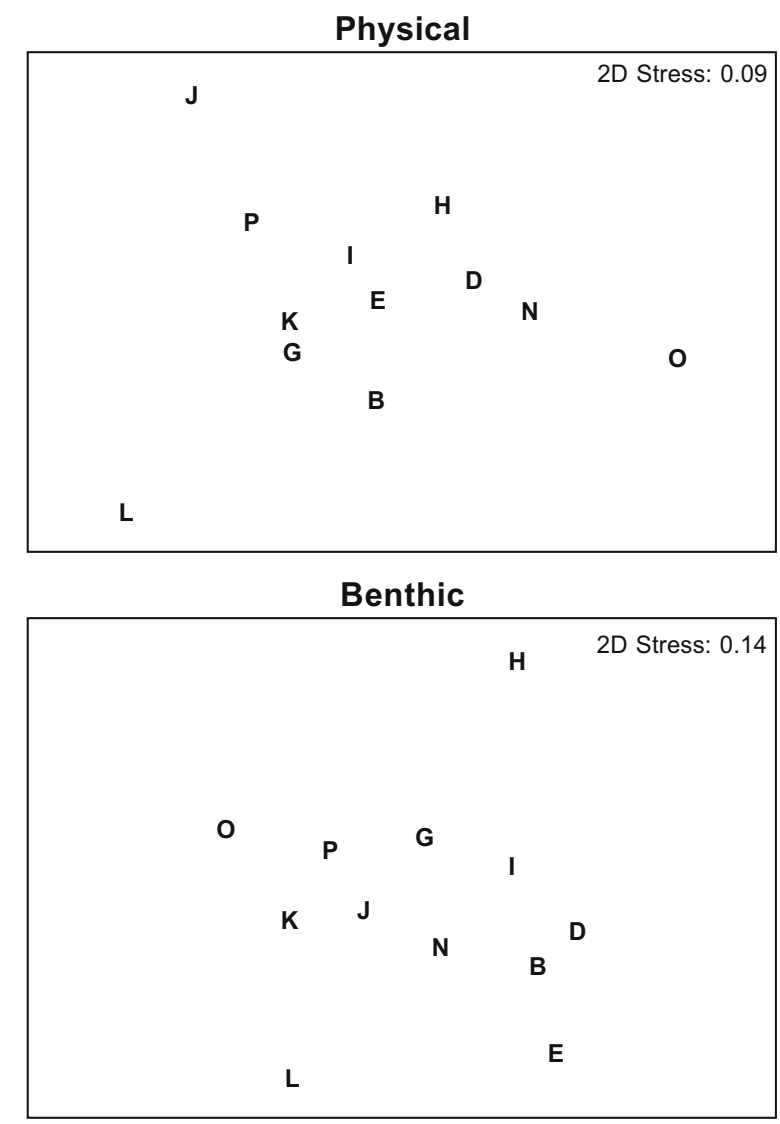

Fish

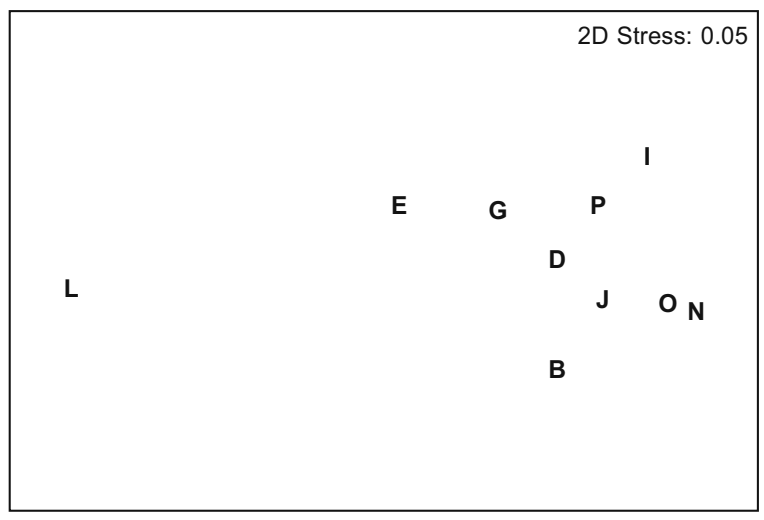

Fig. 2 Nonmetric multidimensional scaling plots displaying similarities among reefs using matrices derived from averaging stations on each reef for physical, benthic, and fish variables. Symbols are the first letter of the reefs as named in Table 1 . Two-dimensional stress values $<0.10$ indicate that the 2-D representation of the relationships among samples provides a good interpretable ordination, and those $<0.2$ are still useful (Clarke and Warwick 2001) 
Fig. 3 Mean gorgonian abundance (individuals per square meter) by genus on each patch reef surveyed $(n=16$ stations per reef except reef $\mathrm{L}$, $n=19)$. Legend lists genera from least to most abundant (top to bottom). Error bars equal one SE for total gorgonians

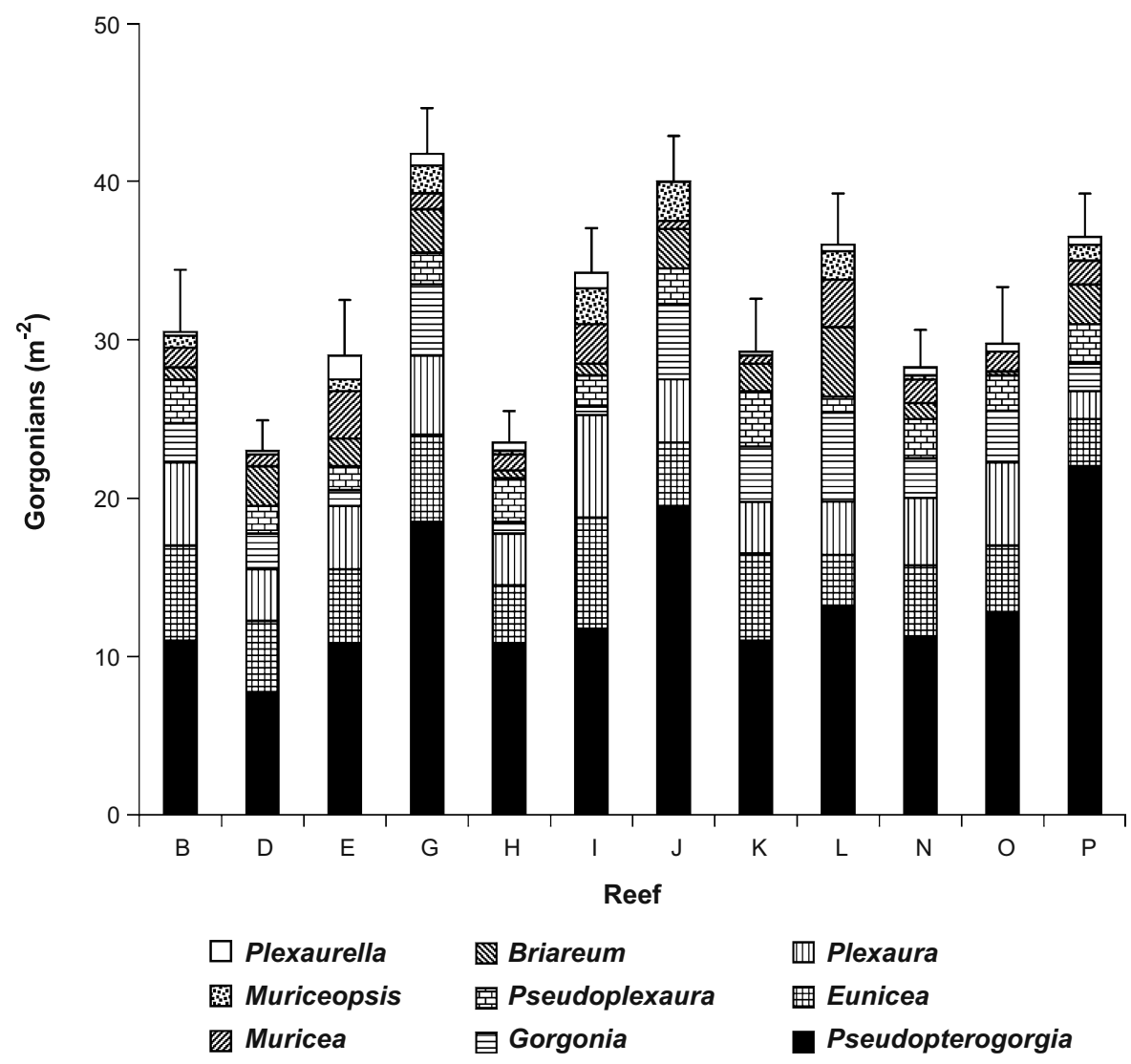

Fig. 4 Mean urchin abundance (individuals per square meter) by species on each patch reef surveyed $(n=16$ stations per reef except L, $n=19)$. Legend lists species from least to most abundant (top to bottom). Error bars equal one SE for total urchins

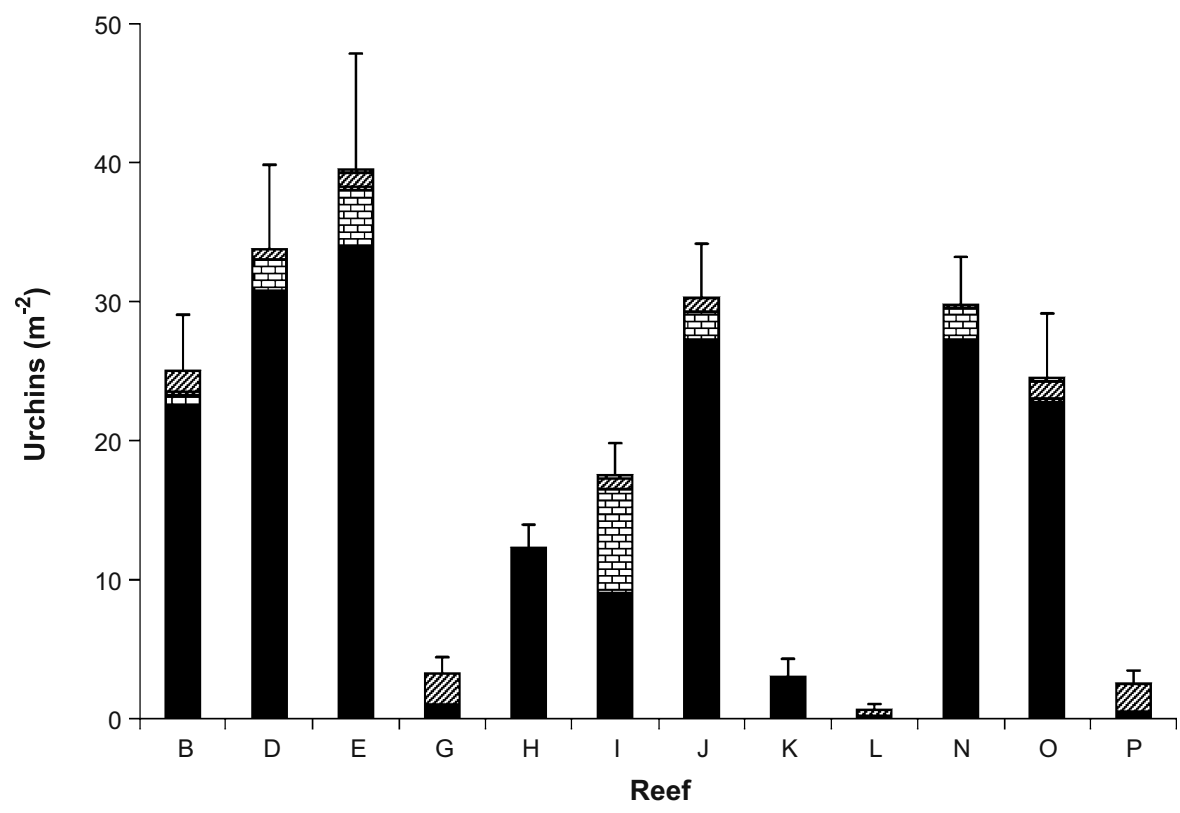

目 Diadema antillarum Eucidaris tribuloides $\mathbf{m}$ Tripneustes ventricosus 
fasts, and Millepora alcicornis) comprised the remainder of the benthic community, contributing about $2-4 \%$ cover each.

Upright gorgonians were abundant on the patch reefs (grand mean $=31.9 \pm 0.9$ individuals per square meter), with $42 \%$ of individuals observed belonging to the genus Pseudopterogorgia (Fig. 3). Gorgonian abundance was significantly different among reefs (ANOVA, $p<$ 0.0001 ), with densities significantly greater at Golf, Lima, and Papa than at Hotel and Delta (Tukey's HSD family alpha $=0.05$ ).

The 888 urchins observed in this study were patchily distributed among reefs (Fig. 4). The most abundant urchin in the study was Echinometra viridis (density ranging from $0.21 \mathrm{~m}^{-2}$ on Lima to $34 \mathrm{~m}^{-2}$ on Echo). Only three $D i$ adema antillarum were tallied within our quadrats. The total count of urchins was significantly different between reefs (Kruskal-Wallis, $p<0.0001$ ). Kruskal-Wallis multiple-comparison groupings showed that reefs Echo, Juliet, November, Delta, Bravo, and Oscar had significantly more urchins than Golf, Kilo, Papa, and Lima. Total urchin abundance did not correlate well with any of the physical or benthic variables measured.

Thirty-one species of scleractinian coral were observed during this study, plus the hydrocoral $M$. alcicornis. Several species were afflicted with various stressors at all or some of the reefs (Table 4). Acropora cervicornis infected with white-band disease was observed on every reef except Hotel, and Siderastrea siderea with darkspot disease was observed on all reefs. Blackband disease infected Montastraea cavernosa at five of the reefs. A total of 125 scleractinian coral recruits were observed within the small-scale sampling quadrats, with an overall recruit density of $10.2 \pm 1.3 \mathrm{~m}^{-2}$. Coral recruit density did not show significant relationships with percent cover of SSS or macroalgae (nor any other physical or benthic variable measured), either on a per-station basis or when data were averaged per reef.

The effect of reef was significant when all benthic variables were included in a multivariate test (ANOSIM global $R=0.122, p=0.001$ ). The similarities among reefs with regards to benthic variables can be visualized in the MDS plot (Fig. 2).
Fish variables

We observed 12,036 reef fish, belonging to 80 species, at the 119 stations where fish were surveyed. Patterns of reef fish abundance among reefs were described in a previous manuscript (Kuffner et al. 2007). The effect of reef was significant when all fish variables were included in a multivariate test (ANOSIM global $R=0.221$, $p=0.001)$. The similarities among reefs with regards to fish variables can be visualized in the MDS plot (Fig. 2). Reef Lima had particularly low abundances of certain groups of fishes (e.g., family Haemulidae) and thus stands out in the MDS plot.

Relationships between physical and benthic variables

Across all stations, $H$. tuna was weakly inversely correlated with EAARL rugosity at the 10-m scale (linear regression, Halimeda data square-root-transformed and rugosity data inverse-transformed, $\left.R^{2}=0.08, p<0.0001\right)$. Further, when the reef effect was taken into account with a two-way ANOVA, results showed that $H$. tuna was more abundant at stations with low substratum rugosity, followed by stations with medium and high rugosity (Table 5, Fig. 5). A Tukey HSD all-pairwise comparison test revealed that $H$. tuna coverage in all three categories of rugosity was significantly different $(p<0.05)$. $H$. tuna abundance was not significantly related to rugosity measured using the chain-transect method, though the trend was the same.

In general, the relations between other specific physical and benthic variables were weak. Gorgonian abundance and genus richness, for example, were negatively correlated with the percent cover of the substratum by rubble $($ small + medium + large $)$, though the relationships were extremely weak (linear regression, abundance: $R^{2}=0.093, p<0.0001$; genus richness: $\left.R^{2}=0.121, p<0.0001\right)$. When the resemblance matrices for all physical and all benthic variables were compared using PRIMER's RELATE procedure, the relationship was not significant (rho $=0.252, p=0.08)$. 


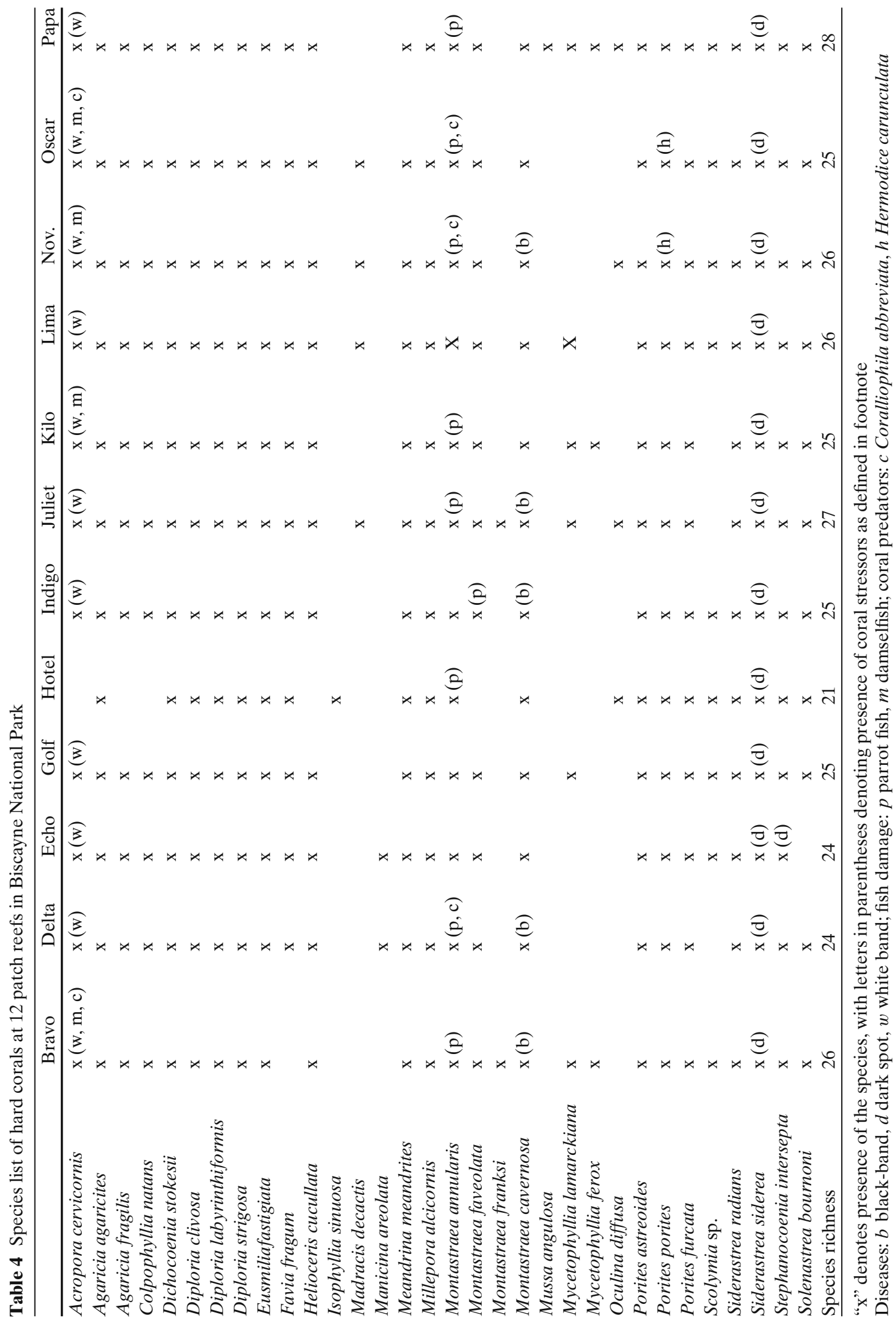


Table 5 Two-way ANOVA results for abundance of juvenile parrot fish (data square-root-transformed) by reef (ten levels) and Dictyota spp. percent cover (low, medium, and high) and H. tuna percent cover (square-root-transformed) by reef (12 levels) and rugosity at the 10-m scale (low, medium, and high)

\begin{tabular}{lrrrrl}
\hline Factor & $d f$ & \multicolumn{1}{c}{ SS } & \multicolumn{1}{c}{ MS } & \multicolumn{1}{c}{$F$} & \multicolumn{1}{c}{$p$} \\
\hline Juvenile parrot fish & & & & & \\
Reef & 9 & 192.98 & 21.44 & 10.50 & $\mathbf{0 . 0 0 0 0}$ \\
Dictyota spp. & 2 & 25.26 & 12.63 & 6.19 & $\mathbf{0 . 0 0 3 0}$ \\
Interaction term & 18 & 35.26 & 1.96 & 0.96 & 0.5123 \\
Error & 89 & 181.68 & 2.04 & & \\
Total & 118 & & & & \\
Halimeda tuna & & & & & \\
Reef & 11 & 54.06 & 4.91 & 2.89 & $\mathbf{0 . 0 0 1 7}$ \\
Rugosity 10 m & 2 & 26.73 & 13.37 & 7.86 & $\mathbf{0 . 0 0 0 6}$ \\
Interaction term & 22 & 33.41 & 1.52 & 0.89 & 0.6048 \\
Error & 160 & 272.23 & 1.70 & & \\
Total & 195 & & & & \\
\hline
\end{tabular}

Significant $p$ values highlighted in bold

Relationships between physical and fish variables

When the resemblance matrices for all physical and all fish variables were compared using PRIMER's RELATE procedure, the relationship was not significant ( rho $=0.249, p=0.17$ ). Relationships between individual physical (e.g., different measures of rugosity) and fish variables were described in a previous manuscript (Kuffner et al. 2007).
Relationships between benthic and fish variables

Some relationships between herbivorous fish and benthic community variables were significant but fairly weak. Percent cover of SSS was positively related to surgeonfish abundance, very weakly so at the station level (linear regression $\left.n=119, R^{2}=0.047, p=0.018\right)$, and nominally stronger (but insignificant) when examined at the "reef" level (Fig. 6a; linear regression $n=$ $\left.10, R^{2}=0.33, p=0.081\right)$. Similarly, mean percent cover of Dictyota spp. was not related to the abundance of roving adult herbivores (scarids plus acanthurids) at the station level (data log-transformed, linear regression $n=119, R^{2}=$ $0.0004, p=0.83)$ but was marginally inversely related at the reef level (Fig. 6b, linear regression $\left.n=10, R^{2}=0.32, p=0.09\right)$. In contrast, juvenile scarid abundance was positively (although very weakly) related to Dictyota spp. percent cover at the station level (Fig. 7a; linear regression $n=119$, data square-root-transformed, $\left.R^{2}=0.032, p=0.05\right)$, but a scatter plot of the residuals from that regression against the reef factor revealed the substantial reef effect (Fig. 7b). When the reef factor was added to the model in a two-way ANOVA, the percent cover of Dictyota was statistically significant in explaining additional variance in juvenile scarid abundance, and a clearer view of the effect can be seen within
Fig. 5 Relationship between percent cover of H. tuna and substratum rugosity (in three categories: low, medium, and high) on 12 patch reefs in Biscayne National Park. Error bars equal one SE and are absent where $n=1$

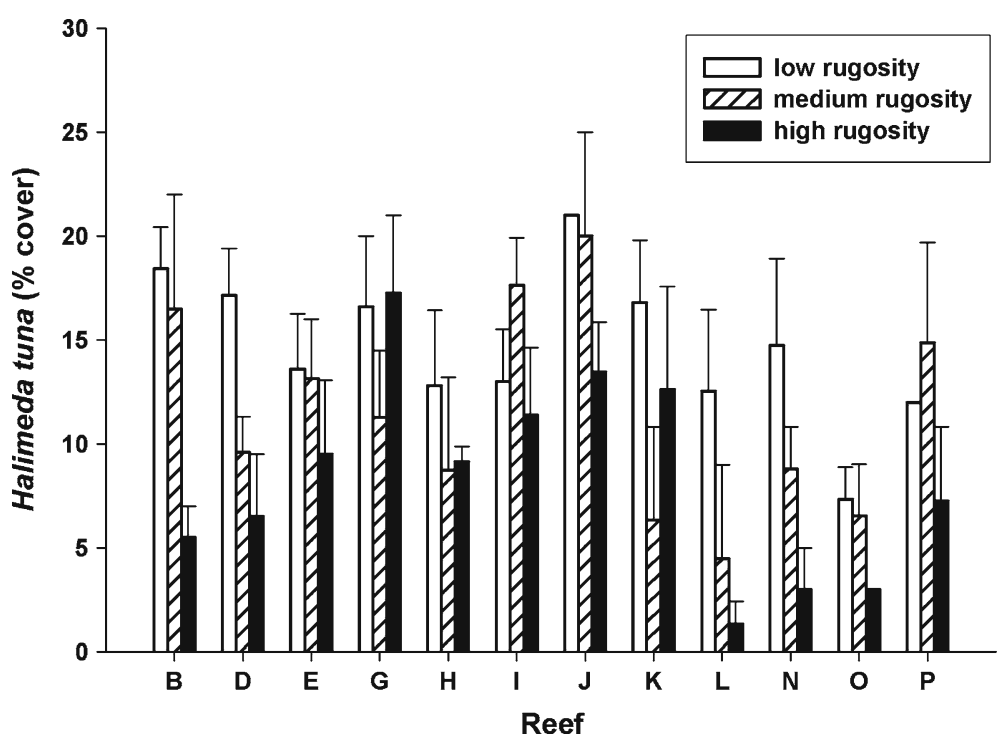




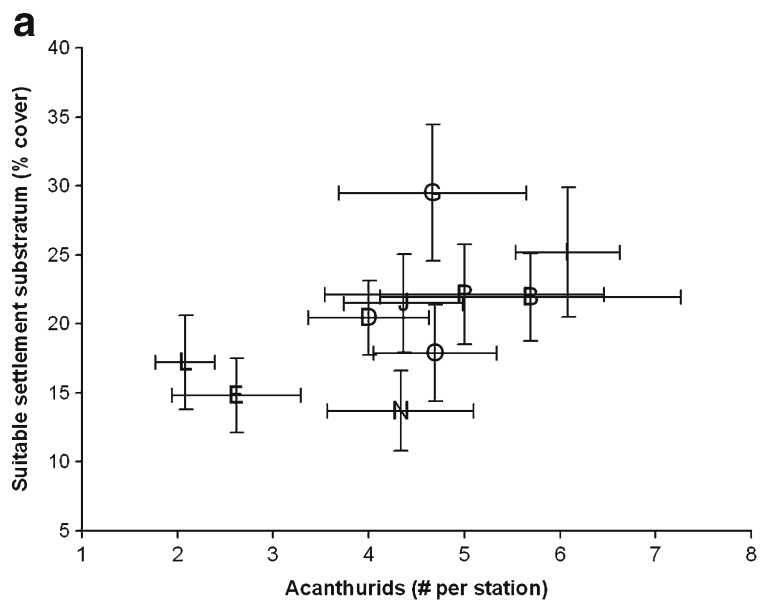

stations in the other coverage categories (medium 9-19\% and low 0-8\%). High Dictyota stations had the highest mean juvenile scarid abundance on eight out of ten reefs (Fig. 7c). Interestingly, converting herbivorous fish abundance to biomass

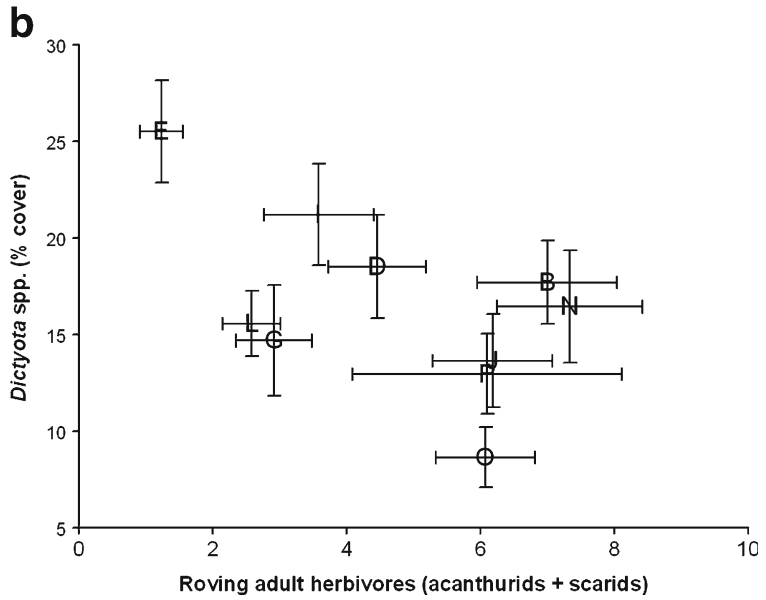

Fig. 6 Reef means with error bars $( \pm 1 \mathrm{SE})$ showing relationship between a the percent cover of suitable settlement substratum and the abundance of acanthurids and $\mathbf{b}$ the percent cover of Dictyota spp. and the abundance of roving adult herbivores (acanthurids + scarids). Letters refer to reef names given in Table 1

each reef (Table 5; Fig. 7c). A Tukey HSD allpairwise comparison test revealed that stations in the high Dictyota spp. coverage category (20-47\% cover) had significantly more juvenile scarids than

Fig. 7 The abundance of juvenile scarids in relation to percent cover of Dictyota spp. shown in a juvenile scarid mean abundance at each station vs. Dictyota spp. percent cover with regression line and $95 \%$ confidence intervals, b residuals from the regression model vs. reef, and $\mathbf{c}$ mean abundance of juvenile scarids per patch reef, broken down into three categories of Dictyota spp. abundance (low, medium, and high). Error bars equal one SE and are absent where $n=1$
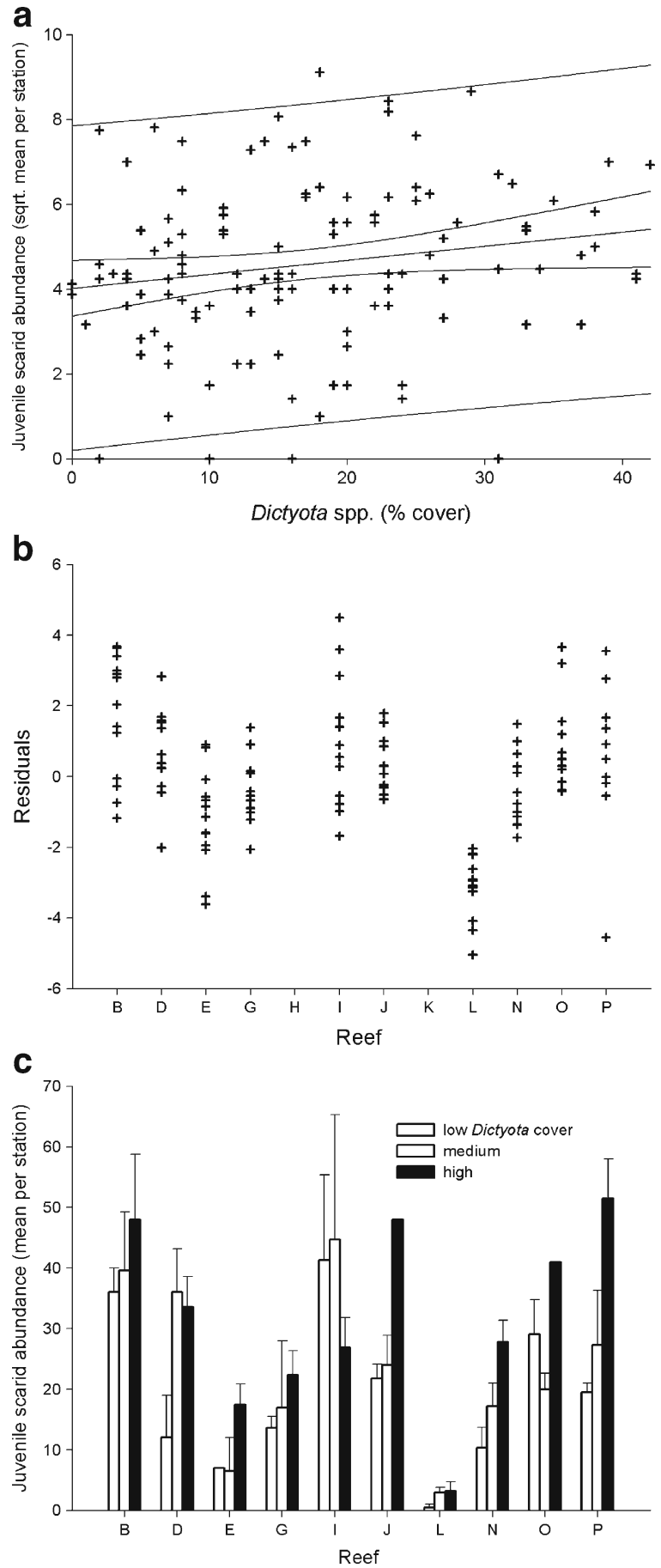
did nothing to improve the relationships between fish and benthic variables (data not shown).

Neither fish species richness nor abundance was related to gorgonian abundance or volume. Relationships between the abundance of the economically important groupers and snappers and benthic variables could not be assessed due to the scarcity of sightings of these fishes during this study. When the resemblance matrices for all benthic and all fish variables were compared using PRIMER's RELATE procedure, the relationship was not significant $(\mathrm{rho}=0.222, p=0.13$ ).

\section{Discussion}

Biological communities on the $12 \mathrm{BNP}$ patch reefs that we surveyed were dominated by gorgonians and encrusting invertebrates, were sparsely populated with live corals afflicted by several diseases, and had fish populations indicative of intensive fishing pressure. However, the densities of recruitsized corals were comparable to other sites in the region. There was a moderate amount of fleshy macroalgae but also a lot of suitable settlement substratum for coral larvae. Urchins were patchily distributed, with populations dominated by $E$. viridis, and $D$. antillarum was nearly absent. Our data agree with other studies indicating that coral (Dupont et al. 2008) and fish populations (Ault et al. 2001) in BNP are still depressed compared to 50 years ago.

The data presented here can help reef resource managers by serving as a baseline assessment of physical habitat, benthic communities, and fish assemblages, but little insight regarding what variables influence community structure within the patch reef habitat type can be drawn from this study. Surveying the biological communities on 12 patch reefs showed that stations within reefs were more homogenous in the abundance of macrophytes, invertebrates, and fish than we had expected. Within-reef variation was less than among-reef variation, as has been previously shown for outer-bank reefs in the Florida Keys (Murdoch and Aronson 1999). Possibly because of the overwhelming reef effect, relationships between physical, benthic, and fish variables were surprisingly weak across all stations. Here, we dis- cuss possible mechanisms behind these patterns, including stochastic larval recruitment, life history characteristics of the major space-occupying species, relatively isolated patches of habitat, human disturbance of populations (e.g., fishing), and the lasting effects of historical events.

\section{Patterns in benthic community structure}

Gorgonians were extremely abundant on the patch reefs surveyed in this study, with an overall mean density of 32 colonies per square meter, comparable to Goldberg's (1973) average density of 34 colonies per square meter on patch reefs off Broward County. We originally hypothesized that the gorgonians found on these patch reefs could be contributing to essential fish habitat by providing protective cover and thus predicted that the abundance or volume of gorgonians could predict certain fish variables. Our data did not support this hypothesis. Gorgonians were abundant on all patch reefs observed in this study, whereas fish showed marked reef effects.

Urchins are important herbivores and bioeroders on coral reefs, and they can either positively or negatively affect reef viability depending upon species, density, and feeding mode. Before the 1983 die-off, D. antillarum played a large role in controlling algal distributions in the shallow Caribbean reef environment (Morrison 1988; Carpenter 1988; Aronson and Precht 2000). The species is presently making a moderate comeback in some parts of the region (Edmunds and Carpenter 2001) but has yet to repopulate the Florida Keys (Chiappone et al. 2002); only three individuals were observed in our study. In contrast, Echinometra spp. (the rock-boring urchins) were quite abundant on some of the patch reefs we surveyed. Densities of these urchins have been shown to increase in the absence of $D$. antillarum (Williams 1981). Reef bioerosion by Echinometra spp. was apparent during our surveys. If reef accretion rates are lower than rates of bioerosion, urchins can cause damage to reef framework. It may be important to monitor the density of Echinometra spp., especially because their main predators (e.g., triggerfish, porcupine fish, stingrays) were never observed during our study. 
Coral recruitment is a key process determining the ability of reef-building coral populations to recover from declines and is an important processoriented variable defining reef health. Measuring the abundance of juvenile corals is one way to estimate coral recruitment rates, though recruit mortality rates remain unknown. The recruit density reported here $(10.2 \pm 1.3$ recruits per square meter) is similar to that reported in other studies in Biscayne Bay (Miller et al. 2000a) and in St. John, US Virgin Islands (Edmunds 2000). Many species of coral larvae require CCA to settle (Morse et al. 1988; Heyward and Negri 1999), and availability of CCA is negatively correlated with macroalgal abundance (Hixon 1997). Dictyota spp., the most abundant fleshy algae observed in this study, was not as abundant on these patch reefs $(15.4 \pm 0.8 \%$ cover) compared to other locations on the Florida reef tract (Lirman and Biber 2000; Beach et al. 2003; Kuffner et al. 2006), whereas SSS was fairly abundant (overall mean $21 \%$ cover). In a study conducted in this area in 1981, Burns (1985) reported that they observed lots of "uncolonized reef substrate." Thus, coral recruitment does not seem to be limited by available substratum (either historically or now) and appears to be occurring at levels comparable to other coral reefs in the region. Our data do not support recruitment failure as a major reason for coral reef decline on the patch reefs in Biscayne National Park. However, the species that we observed as recruits were mostly small colony brooders (e.g., Agaricia spp., Porites spp.) and not the large reef-building species (e.g., Diploria spp., Montastraea spp.) as similarly noted for BNP reefs in the 1980s (Porter and Meier 1992) and from 2001 to 2003 (Lirman and Fong 2007).

Possible mechanisms behind reef-specific patterns in benthic community structure

Most marine organisms reproduce sexually via spawned eggs and sperm that are externally fertilized, followed by a protracted larvaldispersal phase characterized by high mortality rates and very low parental investment per zygote. The relative importance of presettlement and postsettlement processes in determining species population structures is the subject of debate, but, at least for certain species, recruitment processes can explain a considerable amount of temporal and spatial variation in abundance (Keough and Downes 1982; Doherty and Fowler 1994). However, many benthic invertebrates are very successful at asexual propagation. A commonality among many of the major space-occupying organisms that dominate the substratum on these patch reefs is that they all have very successful mechanisms for short-range dispersal. Dictyota menstrualis and Dictyota pulchella, both of which were abundant at our stations, are very successful at establishing new plants via vegetative fragmentation caused by fish grazing (Herren et al. 2006) and hurricanes (Vroom et al. 2005). Halimeda discoidea fragments generated by storms and fish bites can rapidly produce new attachment rhizoids (Walters and Smith 1994), so it is probable that other Halimeda spp. may similarly reproduce via vegetative fragmentation. The encrusting gorgonian, B. asbestinum, produces surface-brooded larvae that are competent to settle immediately after release (Brazeau and Lasker 1990), and branches that are lost due to fragmentation can readily reattach to the substratum to create new colonies (Brazeau and Lasker 1992). E. caribaeorum is a highly aggressive species that can overgrow most other encrusting species (Karlson 1980; Suchanek and Green 1981). P. caribaeorum produces new asexually propagated colonies via fission (Acosta et al. 2005) and fragmentation (Acosta et al. 2001).

Present community composition may be very dependent upon the types of organisms that successfully recruited to the site in the past and were able to take hold and start asexually reproducing, especially since the last physical disturbance event. The importance of prior residents, or "priority" effects, on subsequent community structure via resident-recruit interactions (e.g., predation) has been shown for reef fish (Almany 2003). We suggest priority effects may be important in shaping the encrusting communities we observed, mainly due to asexual propagation leading to preemption of space and possibly predation upon newly arriving larvae by the lush gorgonian community and other filter feeders. This hypothesis could be tested using manipulative field experiments. 
Differential physical disturbance, particularly by Hurricane Andrew in 1992, also could have contributed to reef-specific patterns in benthic community structure. Physical disturbances can have lasting effects on coral communities (Hughes and Connell 1999; Bythell et al. 2000), and impact studies following Hurricane Andrew revealed that disturbance was very patchy (Tilmant et al. 1994; Blair et al. 1994). Further, historical changes to coral communities can affect competitive interactions among benthic organisms many years after the disturbance event (Hughes 1989).

Possible mechanisms to explain lack of benthic-fish community relationships across all survey stations

We found only weak relationships between benthic and fish community attributes across all stations. Previous studies on fish community structure have shown high levels of variance explained by "reef" with little explained by habitat variables (Sale and Douglas 1984; Syms and Jones 2000), but others incorporating a wider range of habitats have found that habitat variables explain a large amount of variance in fish community structure (Chittaro 2004; Gratwicke and Speight 2005). Relationships between habitat and fish have also been revealed in cases where the fish communities involved (e.g., damselfish and other herbivores) were directly affecting benthic community structure, particularly with respects to the algal assemblage (Hixon 1997) and bioerosion of the substratum (e.g., parrot fish, Bellwood and Choat 1990). In contrast, herbivorous fish may respond to food availability (Williams et al. 2001; Russ 2003), rather than affecting the benthic community, in places where they are not food-limited. Herbivorous fish in the Caribbean were thought to be food-limited before the $D$. antillarum dieoff in 1983 (Carpenter 1988) but not since then (Williams and Polunin 2001). Our results, showing only weak or positive (in the case of juvenile parrot fish) relationships between herbivorous fish and fleshy algae abundance, indicate that herbivorous fish do not lack food in Biscayne National Park. Further evidence for the lack of food limitation for herbivorous fish on patch reefs in the
Florida Keys was recently provided by Paddack et al. (2006).

Chronic human disturbance of fish populations could provide an explanation for the lack of relationships between habitat and fish community variables. The low abundance of predators and strong dominance by herbivores and juveniles strongly indicate that fishing is a major factor structuring fish populations on BNP patch reefs. Historically, these patch reefs were wellpopulated with red, black, and Nassau grouper, mutton snapper, and hogfish (Jaap 1984), all of which are prized as food fish and were nearly or entirely absent in our surveys. Fishing can have substantial effects on fish community structure and distribution of trophic guilds, usually increasing the ratio between herbivorous fish and piscivores (Friedlander and DeMartini 2002). In our study, there were approximately nine herbivores for every piscivore. Judging from the amount of derelict fishing gear observed on the reefs, the skewed size distribution toward small fishes, and the almost complete absence of many target species observed in this study, fishing pressure has undoubtedly affected reef fish community structure in BNP. An extensive overview, database assimilation, and modeling effort revealed the extremely poor status of fish resources in BNP (Ault et al. 2001). When the habitat is underpopulated with fish, relationships between habitat and fish assemblage parameters can be hard to detect, as suggested for grouper and adult fishes in the US Virgin Islands by Grober-Dunsmore et al. (2007).

Evidence for within-reef relationships between fish and benthic variables

Macroalgal abundance was inversely correlated with herbivorous fish biomass in a Caribbeanwide study (Williams and Polunin 2001). When averaged across reefs, our data indicate a weak positive relationship between abundance of acanthurids and SSS and an inverse relationship between Dictyota spp. percent cover and the abundance of roving adult herbivores (scarids plus acanthurids). Although converting our data to biomass did not improve the relationships observed, our grand mean biomass and corresponding algal percent cover estimates fit well with 
the large-scale trends reported in Williams and Polunin (2001). Our grand means for acanthurids $\left(1.92 \pm 0.20 \mathrm{~g} \mathrm{~m}^{-2}\right)$, scarids $\left(6.49 \pm 0.49 \mathrm{~g} \mathrm{~m}^{-2}\right)$, and macroalgae (the sum of our Dictyota spp. and $H$. tuna: $27.1 \pm 1.1 \%$ ) result in data points that fall very close to those reported from Grand Cayman (Williams and Polunin 2001). Additionally, plots of our grand means for SSS, which is similar to their "cropped substratum" category, together with our acanthurid and scarid grand means, would lie close to sites in Jamaica. Across all stations, however, there was little variance in Dictyota spp. abundance explained by scarid or acanthurid densities. Compared to data in Williams and Polunin (2001), our sites would have fallen very close to each other if overlain on their far-ranging spread of data points from around the Caribbean basin.

In contrast to what we expected, when the reef effect was taken into consideration, juvenile parrot fish abundance was positively correlated with Dictyota percent cover, indicating that the canopy formed by the algae may provide a nursery habitat for parrot fish. McAfee and Morgan (1996) found that four out of five species of parrot fish studied showed ontogenetic shifts in habitat/food use, spending time as juveniles associated with scattered algal mats on pavement and then moving to the reef slope as adults. In support of this behavioral pattern, Paddack et al. (2006) found that the patch reef environment in the Florida Keys harbored smaller herbivorous fish than outer reefs, indicating that the patch reefs may provide a stepping-stone to adult habitat farther out on the shelf.

\section{Conclusions}

Our study revealed that the overall relationships predicted among physical, benthic, and fish variables were insignificant and were usually overwhelmed by the reef effect. Stations within patch reefs had more in common with each other than was to be expected if all patch reefs constituted a homogenous habitat. Reefs were unique with respect to benthic and fish community structure, and no variable that we measured could explain a significant portion of the variance observed among stations. The lack of relationships between and among biological communities and habitat observed is consistent with several mechanisms, including stochastic larval dispersal, priority effects of early colonizers, and human disturbance (fishing). If Biscayne National Park enacts "notake"-protected areas as planned and fish populations begin to recover, relationships between fish assemblages and benthic communities may become more closely linked.

Acknowledgements The US Geological Survey (Geologic Discipline, Coastal and Marine Geology Program, and Biological Resource Discipline, Terrestrial, Freshwater, and Marine Ecosystems Program) funded this project. This work was performed under the National Park Service permit \# BISC-2003-SCI-0046. We thank R. Curry (Biscayne National Park) for his support of our work and V. Bonito for help in the field including gorgonian and coral identification. We dedicate this work to the memory of Capt. Barry Denton, whom we will greatly miss. He was a great supporter of USGS coral reef research and always kept us safe and comfortable aboard the $M / V$ "Winning Ticket." We also thank W. Jaap, G. Piniak, J. Lisle, J. Morrison, and several anonymous reviewers for helpful suggestions that greatly improved the manuscript. Any use of trade names herein was for descriptive purposes only and does not imply endorsement by the US Government.

Open Access This article is distributed under the terms of the Creative Commons Attribution Noncommercial License which permits any noncommercial use, distribution, and reproduction in any medium, provided the original author(s) and source are credited.

\section{References}

Acosta, A., Sammarco, P. W., \& Duarte, L. F. (2001). Asexual reproduction in a zoanthid by fragmentation: The role of exogenous factors. Bulletin of Marine Science, $68(3), 363-381$.

Acosta, A., Sammarco, P. W., \& Duarte, L. F. (2005). New fission processes in the zoanthid Palythoa caribaeorum: Description and quantitative aspects. Bulletin of Marine Science, 76(1), 1-26.

Almany, G. R. (2003). Priority effects in coral reef fish communities. Ecology, 84(7), 1920-1935. doi:10.1890/ 0012-9658(2003)084[1920:PEICRF]2.0.CO;2.

Aronson, R. B., \& Precht, W. F. (2000). Herbivory and algal dynamics on the coral reef at Discovery Bay, Jamaica. Limnology and Oceanography, 45(1), 251-255.

Ault, J. S., Smith, S. G., Meester, G. A., Juo, J., \& Bohnsack, J. A. (2001). Site characterization for 
Biscayne National Park: Assessment of fisheries resources and habitats (p. 156). NOAA Technical Memorandum NMFS-SEFSC-468.

Beach, K., Walters, L., Borgeas, H., Smith, C., Coyer, J., \& Vroom, P. (2003). The impact of Dictyota spp. on Halimeda populations of Conch Reef, Florida Keys. Journal of Experimental Marine Biology and Ecology, 297, 141-159. doi:10.1016/j.jembe.2003.07.003.

Bellwood, D. R., \& Choat, J. H. (1990). A functional analysis of grazing in parrot fishes (family Scaridae): The ecological implications. Environmental Biology of Fishes, 28, 189-214. doi:10.1007/BF00751035.

Blair, S. M., McIntosh, T. L., \& Mostkoff, B. J. (1994). Impacts of Hurricane Andrew on the offshore reef systems of central and northern Dade County, Florida. Bulletin of Marine Science, 54(3), 961-973.

Bohnsack, J. A., \& Bannerot, S. P.(1986). A stationary visual census technique for quantitatively assessing community structure of coral reef fishes (p. 15). NOAA Technical Report 41.

Brazeau, D. A., \& Lasker, H. R. (1990). Sexual reproduction and external brooding by the Caribbean gorgonian Briareum asbestinum. Marine Biology (Berlin), 104, 465-474. doi:10.1007/BF01314351.

Brazeau, D. A., \& Lasker, H. R. (1992). Growth rates and growth strategy in a clonal marine invertebrate, the Caribbean octocoral Briareum asbestinum. The Biological Bulletin, 183, 269-277. doi:10.2307/1542214.

Brock, J. C., Wright, C. W., Kuffner, I. B., Hernandez, R., \& Thompson, P. (2006a). Airborne lidar sensing of massive stony coral colonies on patch reefs in the northern Florida reef tract. Remote Sensing of Environment, 104(1), 31-42. doi:10.1016/j.rse.2006.04.017.

Brock, J. C., Wright, C. W., Patterson, M., Nayegandhi, A., Patterson, J., Harris, M. S., \& Mosher, L. (2006b). USGS-NPS-NASA EAARL submarine topography: Biscayne National Park. US Geological Survey Open File Report 2006-1118.

Burns, T. P. (1985). Hard-coral distribution and coldwater disturbances in South Florida: Variation with depth and location. Coral Reefs, 4, 117-124. doi:10.1007/BF00300870.

Bythell, J. C., Hillis-Starr, Z. M., \& Rogers, C. S. (2000). Local variability but landscape stability in coral reef communities following repeated hurricane impacts. Marine Ecology Progress Series, 204, 93-100. doi:10.3354/meps204093.

Carpenter, R. C. (1988). Mass mortality of a Caribbean sea urchin: Immediate effects on community metabolism and other herbivores. Proceedings of the National Academy of Sciences of the United States of America, 85, 511-514. doi:10.1073/pnas.85.2.511.

Chapman, M. R., \& Kramer, D. L. (2001). Gradients in coral reef fish density and size across the Barbados Marine Reserve boundary: Effects of reserve protection and habitat characteristics. Marine Ecology Progress Series, 181, 81-96. doi:10.3354/meps181081.

Chiappone, M., \& Sullivan, K. M. (1997). Rapid assessment of reefs in the Florida Keys: Results from a synoptic survey. In Proc 8th int coral reef symp (pp. 1509-1514). Panama.
Chiappone, M., Swanson, D. W., Miller, S. L., \& Smith, S. G. (2002). Large-scale surveys on the Florida Reef Tract indicate poor recovery of the long-spined sea urchin Diadema antillarum. Coral Reefs, 21(2), 155-159.

Chittaro, P. M. (2004). Fish-habitat associations across multiple spatial scales. Coral Reefs, 23(2), 235-244. doi:10.1007/s00338-004-0376-z.

Clarke, K. R., \& Warwick, R. M. (2001). Change in marine communities: An approach to statistical analysis and interpretation (2nd ed.). Plymouth: PRIMER-E Ltd.

Connell, J. H. (1978). Diversity in tropical rain forests and coral reefs. Science, 199, 1302-1310. doi:10.1126/ science.199.4335.1302.

Connolly, S. R., Hughes, T. P., Bellwood, D. R., \& Karlson, R. H. (2005). Community structure of corals and reef fishes at multiple scales. Science, 309, 13631365. doi:10.1126/science.1113281.

Dahl, A. L. (1973). Surface area in ecological analysis: Quantification of benthic coral-reef algae. Marine Biology (Berlin), 23, 239-249. doi:10.1007/BF00389331.

Doherty, P., \& Fowler, T. (1994). An empirical test of recruitment limitation in a coral reef fish. Science, 263, 935-939. doi:10.1126/science.263.5149.935.

Dupont, J. M., Jaap, W. C., \& Hallock, P. (2008). A retrospective analysis and comparative study of stony coral assemblages in Biscayne National Park, FL (19772000). Caribbean Journal of Science, 44(3), 334-344.

Eagle, J. V., Jones, G. P., \& McCormick, M. I. (2001). A multi-scale study of the relationships between habitat use and the distribution and abundance patterns of three coral reef angelfishes (Pomacanthidae). Marine Ecology Progress Series, 214, 253-265. doi:10.3354/meps214253.

Edmunds, P. J. (2000). Patterns in the distribution of juvenile corals and coral reef community structure in St. John, US Virgin Islands. Marine Ecology Progress Series, 202, 113-124. doi:10.3354/meps202113.

Edmunds, P. J., \& Carpenter, R. C. (2001). Recovery of Diadema antillarum reduces macroalgal cover and increases abundance of juvenile corals on a Caribbean reef. Proceedings of the National Academy of Sciences of the United States of America, 98(9), 5067-5071. doi:10.1073/pnas.071524598.

Friedlander, A. M., \& DeMartini, E. E. (2002). Contrasts in density, size, and biomass of reef fishes between the northwestern and the main Hawaiian islands: The effects of fishing down apex predators. Marine Ecology Progress Series, 230, 253-264. doi:10.3354/meps230253.

Gardner, T. A., Cote, I. M., Gill, J. A., Grant, A., \& Watkinson, A. R. (2003). Long-term region-wide declines in Caribbean corals. Science, 301, 958-960. doi:10.1126/science.1086050.

Ginsburg, R. N., Gischler, E., \& Kiene, W. E. (2001). Partial mortality of massive reef-building corals: An index of patch reef condition, Florida reef tract. Bulletin of Marine Science, 69(3), 1149-1173.

Goldberg, W. M. (1973). The ecology of the coraloctocoral communities off the southeast Florida coast: 
Geomorphology, species composition, and zonation. Bulletin of Marine Science, 23(3), 465-488.

Graham, N. A. J., Wilson, S. K., Jennings, S., Polunin, N. V. C., Bijoux, J. P., \& Robinson, J. (2006). Dynamic fragility of oceanic coral reef ecosystems. Proceedings of the National Academy of Sciences of the United States of America, 103(22), 8425-8429. doi:10.1073/pnas.0600693103.

Gratwicke, B., \& Speight, M. R. (2005). The relationship between fish species richness, abundance and habitat complexity in a range of shallow tropical marine habitats. Journal of Fish Biology, 66, 650-667. doi:10.1111/j.0022-1112.2005.00629.x.

Greenstein, B. J., \& Pandolfi, J. M. (1997). Preservation of community structure in modern reef coral life and death assemblages of the Florida Keys: Implications for the Quaternary fossil record of coral reefs. Bulletin of Marine Science, 61(2), 431-452.

Grober-Dunsmore, R., Frazer, T. K., Lindberg, W. J., \& Beets, J. (2007). Reef fish and habitat relationships in a Caribbean seascape: The importance of reef context. Coral Reefs, 26, 201-216. doi:10.1007/ s00338-006-0180-z.

Halpern, B. S., \& Warner, R. R. (2002). Marine reserves have rapid and lasting effects. Ecology Letters, 5, 361366. doi:10.1046/j.1461-0248.2002.00326.x.

Herren, L. W., Walters, L. J., \& Beach, K. S. (2006). Fragment generation, survival, and attachment of Dictyota spp. at Conch Reef in the Florida Keys, USA. Coral Reefs, 25, 287-295. doi:10.1007/s00338-006-0096-7.

Heyward, A. J., \& Negri, A. P. (1999). Natural inducers for coral larval metamorphosis. Coral Reefs, 18, 273-279. doi:10.1007/s003380050193.

Hixon, M. A. (1997). Effects of reef fishes on corals and algae. In: C. E. Birkeland (Ed.), Life and death of coral reefs (pp. 230-248). New York: Chapman and Hall.

Hoegh-Guldberg, O. (1999). Climate change, coral bleaching and the future of the world's coral reefs. Australian Journal of Marine and Freshwater Research, 50, 839866. doi:10.1071/MF99078.

Hughes, T. P. (1989). Community structure and diversity of coral reefs: The role of history. Ecology, 70(1), 275279. doi:10.2307/1938434.

Hughes, T. P. (1994). Catastrophes, phase shifts, and largescale degradation of a Caribbean coral reef. Science, 265, 1547-1551. doi:10.1126/science.265.5178.1547.

Hughes, T. P., \& Connell, J. H. (1999). Multiple stressors on coral reefs: A long-term perspective. Limnology and Oceanography, 44(3), 932-940.

Jaap, W. C. (1984). The ecology of the South Florida coral reefs: A community profile (p. 138). Minerals Management Service, MMS 84-0038.

Jones, J. A. (1977). Morphology and development of southeastern Florida patch reefs. In Proceedings of the 3 rd international coral reef symposium (pp. 231-235). Miami.

Karlson, R. H. (1980). Alternative competitive strategies in a periodically disturbed habitat. Bulletin of Marine Science, 30(4), 894-900.

Keller, B. D., \& Causey, B. D. (2005). Linkages between the Florida Keys National Marine Sanctuary and the South Florida Ecosystem Restoration Initiative. Ocean and Coastal Management, 48, 869-900. doi:10.1016/j.ocecoaman.2005.03.008.

Keough, M. J., \& Downes, B. J. (1982). Recruitment of marine invertebrates: The role of active larval choices and early mortality. Oecologia, 54, 348-352. doi:10.1007/BF00380003.

Kuffner, I. B., Walters, L. J., Becerro, M. A., Paul, V. J., Ritson-Williams, R., \& Beach, K. S. (2006). Inhibition of coral recruitment by macroalgae and cyanobacteria. Marine Ecology Progress Series, 323, 107-117. doi:10.3354/meps323107.

Kuffner, I. B., Brock, J. C., Grober-Dunsmore, R., Bonito, V. E., Hickey, T. D., \& Wright, C. W. (2007). Relationships between reef fish communities and remotely sensed rugosity measurements in Biscayne National Park, Florida, U.S.A. Environmental Biology of Fishes, 78(1), 71-82. doi:10.1007/s10641-006-9078-4.

Kuffner, I. B., Brock, J. C., Grober-Dunsmore, R., Hickey, T. D., Bonito, V., Bracone, J. E., \& Wright, C. W. (2008). Biological communities and geomorphology of patch reefs in Biscayne National Park, Florida, U.S.A. US Geological Survey Open File Report 2008-1330.

Lewis, J. B. (2004). Has random sampling been neglected in coral reef faunal surveys? Coral Reefs, 23(2), 192194. doi:10.1007/s00338-004-0377-y.

Lirman, D., \& Biber, P. (2000). Seasonal dynamics of macroalgal communities of the northern Florida reef tract. Botanica Marina, 43, 305-314. doi:10.1515/ BOT.2000.033.

Lirman, D., \& Fong, P. (2007). Is proximity to land-based sources of coral stressors an appropriate measure of risk to coral reefs? An example from the Florida Reef Tract. Marine Pollution Bulletin, 54, 779-791. doi:10.1016/j.marpolbul.2006.12.014.

Maliao, R. J., Turingan, R. G., \& Lin, J. (2008). Phase-shift in coral reef communities in the Florida Keys National Marine Sanctuary (FKNMS), USA. Marine Biology (Berlin), 154, 841-853. doi:10.1007/s00227-008-0977-0.

Marszalek, D. S., Babashoff, G., Noel, M. R., \& Worley, D. R. (1977). Reef distribution in South Florida . In Proceedings of the 3 rd international coral reef symposium (pp. 223-229). Miami.

McAfee, S. T., \& Morgan, S. G. (1996). Resource use by five sympatric parrot fishes in the San Blas Archipelago, Panama. Marine Biology (Berlin), 125, 427-437.

McClanahan, T. R. (1994). Kenyan coral reef lagoon fish: Effects of fishing, substrate complexity, and sea urchins. Coral Reefs, 13, 231-241. doi:10.1007/ BF00303637.

Miller, M. W., Weil, E., \& Szmant, A. M. (2000a). Coral recruitment and juvenile mortality as structuring factors for reef benthic communities in Biscayne National Park, USA. Coral Reefs, 19(2), 115-123. doi:10.1007/s003380000079.

Miller, S. L., Swanson, D. W., \& Chiappone, M. (2000b). Multiple spatial scale assessment of coral reef and hard-bottom community structure in the Florida Keys National Marine Sanctuary . In Proceedings of the 9th international coral reef symposium (pp. 69-74). Bali, Indonesia. 
Morrison, D. (1988). Comparing fish and urchin grazing in shallow and deeper coral reef algal communities. Ecology, 69(5), 1367-1382. doi:10.2307/1941634.

Morse, D. E., Hooker, N., Morse, A. N. C., \& Jensen, R. A. (1988). Control of larval metamorphosis and recruitment in sympatric agariciid corals. Journal of Experimental Marine Biology and Ecology, 116, 193217. doi:10.1016/0022-0981(88)90027-5.

Murdoch, T. J. T., \& Aronson, R. B. (1999). Scaledependent spatial variability of coral assemblages along the Florida Reef Tract. Coral Reefs, 18(4), 341351. doi:10.1007/s003380050210.

Paddack, M. J., Cowen, R. K., \& Sponaugle, S. (2006). Grazing pressure of herbivorous coral reef fishes on low coral-cover reefs. Coral Reefs, 25, 461-472. doi:10.1007/s00338-006-0112-y.

Pandolfi, J. M., \& Jackson, J. B. C. (2006). Ecological persistence interrupted in Caribbean coral reefs. Ecology Letters, 9, 818-826. doi:10.1111/j.1461-0248. 2006.00933.x.

Pandolfi, J. M., Bradbury, R. H., Sala, E., Hughes, T. P., Bjorndal, K. A., Cooke, R. G., et al. (2003). Global trajectories of the long-term decline of coral reef ecosystems. Science, 301, 955-958. doi:10.1126/ science. 1085706.

Pandolfi, J. M., Jackson, J. B. C., Baron, N., Bradbury, R. H., Guzman, H. M., Hughes, T. P., et al. (2005). Are U.S. coral reefs on the slippery slope to slime? Science, 307, 1725-1726. doi:10.1126/science.1104258.

Porter, J. W., \& Meier, O. W. (1992). Quantification of loss and change in Floridian reef coral populations. American Zoologist, 32, 625-640.

Porter, J. W., Kosmynin, V., Patterson, K. L., Porter, K. G., Jaap, W. C., Wheaton, J. L., et al. (2002). Detection of coral reef change by the Florida Keys Coral Reef Monitoring Project. In: J. W. Porter \& K. G. Porter (Eds.), The everglades, Florida Bay, and coral reefs of the Florida Keys: An ecosystem sourcebook (pp. 749769). Boca Raton: CRC Press.

Risk, M. J. (1972). Fish diversity on a coral reef in the Virgin Islands. Atoll Research Bulletin, 153, 1-6.

Russ, G. R. (2003). Grazer biomass correlates more strongly with production than with biomass of algal turfs on a coral reef. Coral Reefs, 22, 63-67.

Sale, P. F., \& Douglas, W. A. (1984). Temporal variability in the community structure of fish on coral patch reefs and the relation of community structure to reef structure. Ecology, 65(2), 409-422. doi:10.2307/ 1941404.

Suchanek, T. H., \& Green, D. J. (1981). Interspecific competition between Palythoa caribaeorum and other sessile invertebrates on St. Croix reefs, US Virgin Islands. In Proceedings of the 4th international coral reef symposium (pp. 679-684). Manila.

Syms, C. (1995). Multi-scale analysis of habitat association in a guild of blennioid fishes. Marine Ecology Progress Series, 125, 31-43. doi:10.3354/meps125031.

Syms, C., \& Jones, G. P. (2000). Disturbance, habitat structure, and the dynamics of a coral-reef fish community. Ecology, 81(10), 2714-2729.

Tilmant, J. T., Curry, R. W., Jones, J., Szmant, A., Zieman, J. C., Flora, M., et al. (1994). Hurricane Andrew's effects on marine resources. Bioscience, 44(4), 230-237. doi:10.2307/1312227.

Vroom, P., Walters, L., Beach, K., Coyer, J., Smith, J., Abgrall, M., et al. (2005). Hurricane induced propagation and rapid regrowth of the weedy brown alga Dictyota in the Florida Keys. Florida Scientist, 68, 161-174.

Walters, L. J., \& Smith, C. M. (1994). Rapid rhizoid production in Halimeda discoidea Decaisne (Chlorophyta, Caulerpales) fragments: A mechanism for survival after separation from adult thalli. Journal of Experimental Marine Biology and Ecology, 175(1), 105-120. doi:10.1016/00220981(94)90178-3.

Wilkinson, C. R. (1999). Global and local threats to coral reef functioning and existence: Review and predictions. Marine \& Freshwater Research, 50, 867-878. doi:10.1071/MF99121.

Williams, A. H. (1981). An analysis of competitive interactions in a patchy back-reef environment. Ecology, 62(4), 1107-1120. doi:10.2307/1937008.

Williams, I. D., \& Polunin, N. V. C. (2001). Large-scale associations between macroalgae cover and grazer biomass on mid-depth reefs in the Caribbean. Coral Reefs, 19(4), 358-366.

Williams, I. D., Polunin, N. V. C., \& Hendrick, V. J. (2001). Limits to grazing by herbivorous fishes and the impact of low coral cover on macroalgal abundance on a coral reef in Belize. Marine Ecology Progress Series, 222, 187-196. doi:10.3354/meps222187. 